\title{
SERIES EDITOR'S INTRODUCTION
}

It has been more than twenty years since Princeton University Press published J. Robert Barth's The Symbolic Imagination: Coleridge and the Romantic Tradition. The book, praised by a range of distinguished reviewers with differing critical orientations, has been out of print and difficult to get for some time. Because of its strong emphasis on the religious dimension in Coleridge's aesthetic theory, it seemed appropriate that Fordham University Press consider it as the third volume in its developing Religion and Literature Series. And Barth, a continuing presence in Romantic studies and in the discourse interested in connections between art and religion, was eager to revisit his 1977 volume and, while not altering his basic argument, to develop it more fully and bring it into the notable contemporary dialogue on Coleridge's theory of imagination. Our reviewers agreed that this new and expanded edition fulfilled his expectations.

This volume, then, is a notably fresh and engaging study. Barth's distinction between the eighteenth-century "poetry of reference" and the new Romantic "poetry of encounter," and his strong emphasis on symbol as the agent of encounter that draws us into experience, remain his vital starting-points. And two new chapters, both revealing his continuing reflection, lecturing, and writing on the subjects, explore in even greater depth the theological foundation of Coleridge's idea of symbol and what he calls the scriptural dimension of his imagination. For Barth, the imagination and its symbolic renderings are at the heart of the questing spirit of Romanticism.

What we have here is a "new life" for a superior contribution to Coleridge students and to the rapidly developing field of religious critical discourse. 